\title{
A Computational Model to Access the Impact of Medicinal based Plants for Curing of Type-1 Diabetes Mellitus
}

\section{Pooja Khurana*, Deepak Kumar, Richa Gupta}

Department of Mathematics, Manav Rachna International Institute of Research Studies, Sector-43, Surajkund Road, Faridabad, Haryana, India

Key words: Regulation of glucose-insulin model , Type-1 diabetes.

\section{Abstract}

Diabetes, a fifth leading disease in terms of causing death and having a complex syndrome. Many anti-diabetic drugs are still in the market but due to their resistance, sideeffects, and toxicity, the effective treatment has been restricted. Focusing on the problem, this paper is focusing on herbal treatment (medicinal plants) for curing diabetes by generalizing the computational model to examine the response of selected medicinal plants on the regulatory model of glucose and insulin for the patients having type-1 diabetes. Glucose and universal insulin variables have been considered in this computational model. How the glucose and insulin behave in the patients suffering from type-1 diabetes has also been shown by obtaining the numerical values with the impact of medicinal plants. The conclusion of this study proposes that blood glucose levels decrease with the impact of parts of the medicinal plant like coriander seeds, black myrobalan, amla, sweet basil, garlic in day by the day consuming.

Here, the immune system attacked the $\beta$-cells, responsible for the production of insulin (Adapa \& Sarangi, 2015).

Type 2 (Adult onset Diabetes): It is non-insulin-dependent diabetes. In this, cells do not respond to the insulin or cells develop resistance to insulin. It occurs Insulin is not being used by fat; muscle and liver cells to take glucose into the body's cells to utilize for energy. Consequently, the body desires supplementary insulin to help glucose penetrate cells (Adapa et al., 2015; Kazi, 2014). However, Diabetes type-2 is the most prevalent type of diabetes ( $\mathrm{Lal}, 2 \mathrm{2016}$ ).

According to WHO (2019), around 422 million adults are suffering from diabetes and around 1.6 million deaths are directly endorsed to diabetes annually. With time, increased concentration of blood glucose can cause severe damage to the heart, kidneys, blood vessels, nerves, eyes.

Gut Microflora is having a significant purpose in the regulation of metabolic activities. Due to the imbalances in the gut microbes, the number of butyrate-producing bacteria decreases resulting in the low level of sulfate and resistance to oxidative stress (Raman, 2016). Further, as per some study, individuals who work on shifts have a $37 \%$ more increased risk as compared to the normal population within an overall increased risk of $9 \%$. This is because, shift workers have to suffer from increased appetite and also their regular sleep-wake cycle disrupted due to which resistance to Type 1 (Juvenile Diabetes): It is insulin-dependent diabetes.

*Corresponding Author: pooja.fet@mriu.edu.in 
insulin develops (Raman, 2016; Gan et al., 2015).

Although several medications such as glucoselowering drugs or anti-diabetic drugs including Metformin, biguanides, sulfonylureas, meglitinide, thiazolidinedione (TZD), dipeptidyl peptidase 4 (DPP-4) inhibitors, sodium-glucose cotransporter (SGLT2) inhibitors, and a-glucosidase inhibitors (Chaudhury et al., 2017; Modak et al., 2007) are available in the market but the results not showing its cure completely. Moreover, drug resistance, toxicity, and side effects are some of the disadvantages of these treatments due to which there is a need to shift these medications towards the some traditional treatments by means of herbal ways.

In the history of medicine, plants are considered as the major source of drugs. Rigveda contains the description of all the curative properties of the medicinal plants. Later, many synthetically derived chemical drugs came into existence which falls due to their disadvantages such as drug resistance, side effects and toxicity. But, in the current scenario, again, traditional medicines (plant-based) are being used in a positive way.

The front line drug- Metformin for treating Diabetes Mellitus, consists of Galega officinalis as an active ingredient that proves to be an efficacious oral glucoselowering agent (Modak et al., 2007).

Medicinal plants "Coccinia indica, Azadirachta indica, Syzygium cumini, Terminalia chebula, Ficus racemosa, Momordica charantia, Swietenia mahagoni, Allium sativum, Eugenia jambolana, Momordica charantia, Ocimum sanctum, Phyllanthus amarus, Pterocarpus marsupium, Tinospora cordifolia, Trigonella foenum graecum and Withania somnifera" have been reported that have effective response in the treatment of Diabetes (Modak et al., 2007; Kooti et al., 2016). These plants help to increase the body's resistance against infection and purif ies the blood. These plants are reported to have a hypoglycemic activity which helps to decrease the glucose level in blood plasma, resulting in a better cure for diabetic patients.

The components of many plants include natural antioxidants, flavonoids, tannins, vitamins $\mathrm{C}$ and $\mathrm{E}$ that retain the ability of $\beta$-cells to secrete insulin and hence decrease blood glucose levels (Kooti et al., 2016).

The components of many plants include natural antioxidants, tannins, vitamins $\mathrm{C}$ and $\mathrm{E}$ that retain the ability of $\beta$-cells to secrete insulin and hence decrease blood glucose levels. These are used as an anti-diabetic and antihyperglycemic remedy in India. Extracts of these medicinal plants can be used to reduce glucose in the blood.

In the given table some of the potential plants have been highlighted with respect to their Active constituents and Mechanism related to anti-diabetic effect or properties.

\section{Methodology:}

The Mathematical Model: it is composed of glucose and insulin level 'G'and'I'. The above system can be described by the ordinary differential equations considering many parameters including the parameter of medicinal plants as well. The differential equation model is:

$$
\begin{aligned}
& d G / d t=-\left(A_{1}-a_{1}\right) G+A_{2} I+G_{b} \\
& d I / d t=-\left(A_{3}+a_{4}\right) I+A_{5}+A_{5} G+I_{b}
\end{aligned}
$$

\section{Variables and parameters are described as:}

$G(t)$ : "Concentration of glucose in blood plasma at timet $(\mathrm{mg} / \mathrm{dl})$ "

$I(t)$ :" Concentration of insulin in plasma at time $t(\mu \mathrm{U} / \mathrm{ml})$ "

$G_{b}$ : "This is the basal value of plasma glucose (mg/dl)"

$I_{b}$ : "This is the basal value of plasma insulin $(\mu \mathrm{U} / \mathrm{ml})$ "

$A_{1}$ : "Insulin independent rate constant of glucose rate uptake in muscles, liver and adipose tissue (min-1)".

$A_{2}$ : "The rate of decrease in tissue glucose uptake ability (min-1)".

$A_{3}$ : "The insulin-independent increase in glucose uptake ability in tissue per unit of insulin concentration $\mathrm{Ib}(\mathrm{min}-2(\mu \mathrm{U} / \mathrm{ml})$ "

$A_{4}$ : "The first-order decay rate for insulin in plasma (min-1) pancreatic ß-cells release insulin"

$A_{5}$ : "The rate of the pancreatic $ß$-cells' release of insulin after the glucose injection and with glucose concentration above $h$ $\left[(\mu \mathrm{U} / \mathrm{ml}) \min ^{-2}(\mathrm{mg} / \mathrm{dl})^{-1}\right] "$

$a_{1}$ : "The rate of change of blood glucose level upon intake of active constituents of medicinal plants".

Eliminating G \& I from set of equations (1) \& (2) we get

$D^{2} G+w^{2} D G+2 \alpha G=s_{1} \ldots .$. (3)

$D^{2} I+w^{2} D I+2 \alpha I=s_{1} \ldots . .(4)$

Where

$w^{2}\left(A_{1}-a_{1}\right)\left(A_{3}+A_{4}\right)-A_{2} A_{5}$ $2 \alpha=\left(A_{1}-a_{1}\right)\left(A_{3}+A_{4}\right)$

$S_{1}=A_{2} I_{b}+\left(A_{3}+A_{4}\right) G_{b}$

$S_{2}=\left(A_{1}-a_{1}\right)+A_{3} G_{b}$

The analytic solution of the proposed mathematical model

If $S_{1}=(t)=e^{\alpha t} \sin w t$ and $S_{2}(t)=0$

$G=e^{\alpha t}[X \cos w t+Y \sin w t+B \sin w t / w]$ (5)

$I=e^{\alpha t}[M \cos w t+N \sin w t](6)$

Numerical solution

Case 1 (a): If a type-1diabetic person in not using medicinal plants in day to day life.

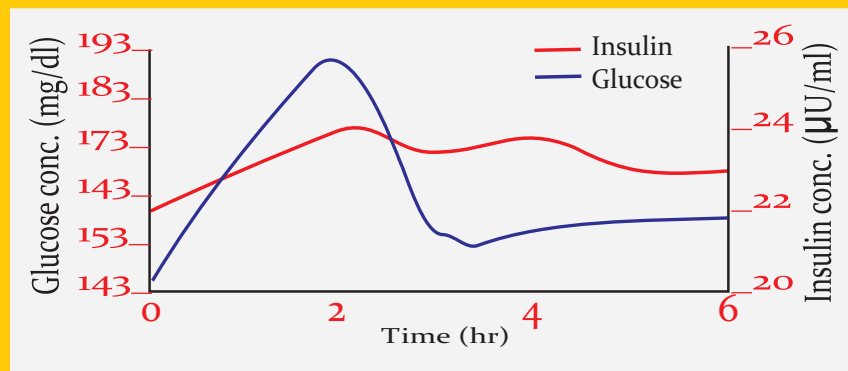

Figure 1(a): Untreated, 6 hours of blood glucose and insulin concentration curve for a patient having type-1 diabetes. 
Table-1: Medicinal plant and their potentiality against the disease

Plant (Common Name): Family

Active constituents Mechanism

References

Allium sativum (Garlic): Alliaceae

Ethyl ether extract Antihyperglycemic activity Patel et al.,

Allicin

S-allyl cystein -

(increase insulin activity)

2012; Singh

sulfoxide (SACS)

Hypoglycemic activity et al., 2010;

(increase insulin discharge Bnouham et

from pancreatic beta cells) al., 2016;

Antioxidant and Modak et

secretagogues activity al., 2007

Coriandrum sativum (Coriander): Apiaceae

P-cymene, linalool Enhances beta cells activity. Rahimi, 2015; Blood glucose lowering Aissaoui et activity.

al., 2011

Phyllanthus emblica (Amla): Euphorbiaceae

Phyllanthin Hypoglycemic activity,

Alkaloids, phenolic anti- oxidant,

compounds, Ahypolipidemic activity

chromium.

Giovannini et

al., 2016; Sri

Sri et al., 2013

Ocimum basilicum (Sweet/ Great basil): Lamiaceae

Eugeno

Methanol-dichlo-

Blood glucose lowering

activity. Anti-hyper-

glycemic activity.

romethane leaf

Glucose transporter

extract, Methanol, Glucose
hexane \& dichloro- activity.

methane extracts

Terminalia chebula

Chloroform

(Black myrobalan): Combretaceae

extract

Anti diabetic and renoprotective effects

Miraj et al., 2016; Kéita et al., 2000; Mbaoji et al., 2014; Kadan et al., 2016.

Rao et al., 2006; Senthil Kumar et al., 2008; Khan

et al., 2015.

Figure 1 (a) represents the behavior of glucose and insulin suffering from type 1 diabetes without using the medicinal plants. It is showing how the level of glucose rises from morning I.e. $50 \mathrm{mg} / \mathrm{DL}$ to $190 \mathrm{mg} / \mathrm{DL}$ within 2.5 hours of breakfast.

Case 1 (b): If a Type-1diabetic person in using medicinal plants in daily life routine for a week.

As per Kusirisin et al. (2009) Value estimation for, Garlic $=0.487 \mathrm{mg} / \mathrm{dl}$; Coriander seeds $=0.306 \mathrm{mg} / \mathrm{dl}$; Sweet Basil=0.296mg/dl; Black Myrobolar=0.063mg/dl; Amla $=0.001 \mathrm{mg} / \mathrm{dl}$.

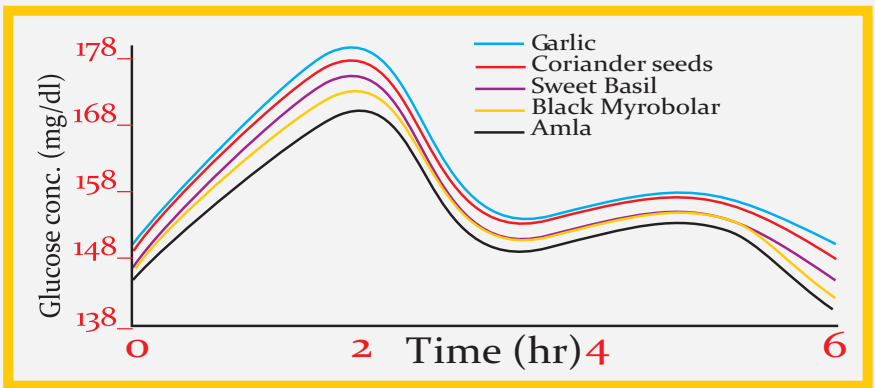

Figure-1(b): Graph of 6 hours of blood glucose and insulin curve for a type-1 diabetic person using medicinal plants.
Figure 1 (b) speaks to the glucose and insulin behavior on the regulatory model of the patient suffering from type 1 diabetes when the patient is using parts of medicinal plants like coriander seeds, black myrobalan, amla, sweet basil, garlic in the diet for a week. It depicts that the glucose level of a type-1 diabetic person has been controlled after using medicinal plants in daily life. Also, the effect of Garlic is maximum due to its hypoglycemic effect.

\section{Conclusion:}

Many anti-diabetic drugs are still available in the market but due to their resistance, toxic and side effects, the effective treatment has been restricted. Herbal treatments (the utilization of therapeutic plants) provide a better approach, cure and the executives' treatment for the patients having diabetes. The generalized Mathematical Model describes the change in the level of blood glucose upon using different parts of the medicinal plant as a drug and their effect on the Glucose- Insulin regulatory system. Different medicinal plants have chosen possess the antihyperglycemic activity due to the presence of active constituents such as flavonoids, tannins, phenolic, and alkaloids which help the diabetic patients in reducing their blood glucose level.

Numerical solutions for each of the plant has been figure out for a week and found to be stable. The graph determines the change in the concentration of blood glucose levels in the patient suffering from type 1 diabetes upon intake of active parts of different medicinal plants. Each of the 5 therapeutic plants picked can reduce the blood glucose level; however, Allium sativum (Garlic) shows the best results in the context of treating type-1 diabetes.

\section{References:}

Adapa, D.\& Sarangi, T.K. (2015): A review on diabetes mellitus: complications, management and treatment modalities. L. Med. Health. Sci., 4(3).

Aissaoui, A., Zizi, S., Israili, Z.H. \&Lyoussi, B. (2011): Hypoglycemic and hypolipidemic effects of Coriandrum sativum L. in Meriones shawi rats. J. Ethnopharmacol., 137(1):652-661.

Bnouham,M., Ziyyat, A., Mekhfi, H., Tahri, A. \& Legssyer, A. (2006): Medicinal plants with potential antidiabetic activityA review of ten years of herbal medicine research (1990200o).Int. J. Diabetes Metab., 14:1-25.

Chaudhury, A., Duvoor, C., Dendi, R., Sena, V., Kraleti, S., Chada, A., Ravilla, R., Marco, A., Shekhawat, N.S., Montales, M.T., Kuriakose, K., Sasapu, A., Beebe, A., Patil, N., Musham, C.K., Lohani, G.P. \& Mirza, W. (2017): Clinical review of antidiabetic drugs: implications for type 2 diabetes mellitus management. Front. Endocrinol.,8:6.

Gan, Y., Yang, C., Tong, X., Sun, H., Cong, Y., Yin, X., Li, L., Cao, S., Dong, X., Gong, Y., Shi, O., Deng, J., Bi, H. \& Lu, Z. :(2015): Shift work and diabetes mellitus: a meta-analysis of observational studies. Occup. Environ. Med., 72(1):72-78.

Giovannini, P., Howes, M.J. \& Edwards, S.E. (2016): Medicinal plants used in the traditional management of diabetes and its sequelae in Central America: A review. L. Ethnopharmacol., 
184:58-71.

Jiang, G., \& Zhang, B.B. (2003): Glucagon and regulation of glucose metabolism. Am. J. Physiol. Endocrinol. Metab.,284(4):E671678.

Kadan,S., Saad, B., Sasson, Y. \& Zaid, H. (2016): In vitro evaluation of anti-diabetic activity and cytotoxicity of chemically analysed Ocimum basilicum extracts. Food Chem., 196:10661074 .

Kazi, S. (2014): Use of traditional plants in diabetes mellitus. Int. J. Pharm., 4(4):283-289.

Kéita, S.M., Vincent, C., Schmit, J.P. \& Bélanger, A. (200o): Essential oil composition of Ocimum basilicum L., $O$. gratissimum L. and O. suave L. in the Republic of Guinea. Flavour Fragrance I.,15(5):339-341.

Khan, M.U., Khalilullah, H., Akhtar, J. \&Elhasan, G.O. (2015):Terminalia chebula: an ephemeral glance. Int. J. Pharm. Pharm. Sci., 7(2):40-43.

Kooti, W., Farokhipour, M., Asadzadeh, Z., Ashtary-Larky, D. \& Asadi-Samani,M. (2016): The role of medicinal plants in the treatment of diabetes: a systematic review. Electron.Physician.,8(1):1832-1842.

Kusirisin, W., Srichairatanakool, S., Lerttrakarnnon, P., Lailerd, N., Suttajit, M., Jaikang, C. \& Chaiyasut, C. (2009):Antioxidative activity, polyphenolic content and antiglycation effect of some Thai medicinal plants traditionally used in diabetic patients. Med. Chem., 5(2):139-147.

Lal, S.B. (2016): Diabetes: Causes, Symptoms and Treatments. Edition-1,Chapter:5, 55-67. Pub. by: Public Health Environment and Social Issues in India.

Lemos, Costa, T.M., Detsch, J.M., Pimazoni-Netto, A., de Almeida, A.C., Sztal-Mazer, S. Tondin de Oliveira, L.M., Nascimento, D.J. \& Réa, R.R. (2011): Glycemic Variability and Mean Weekly Glucose in the Evaluation and Treatment of Blood Glucose in Gestational Diabetes Mellitus; Evidence for Lower Neonatal Complications. L. Diabetes Metab.,2(137):2-5.

Manson, J.E., Ajani, U.A., Liu, S., Nathan, D.M. \& Hennekens, C.H.(2000): A prospective study of cigarette smoking and the incidence of diabetes mellitus among US male physicians. Am. J.Med., 109(7):538-542.

Mbaoji, F.N., Okoli, C.O. \& Ezike, A.C. (2014): Preliminary antihyperglycemic activity-guided studies on the leaf extract and fractions of Ocimum basilicum. L. L. Chem. Pharm. Res., $6(4): 575-580$.
Miraj, S. \& Kiani, S. (2016): Study of pharmacological effect of Ocimum basilicum: A review. Der. Pharmacia, Lett., 8(9): 276-280.

Modak, M., Dixit, P., Londhe, J., Ghaskadbi, S. \& Devasagayam, T.P. (2007): Recent advances in Indian herbal drug research In: Thomas Paul (ed.) Asir devasagayam Indian herbs and herbal drugs used for the treatment of diabetes. J. Clin. Biochem. Nutr.,40(3):163-173.

Patel, D.K., Prasad, S.K., Kumar, R. \& Hemalatha, S. (2012): An overview on antidiabetic medicinal plants having insulin mimetic property. Asian Pac. J. Trop. Biomed., 2(4):320-330.

Rahimi, M. (2015): A review: anti diabetic medicinal plants used for diabetes mellitus. Bull. Environ. Pharmacol. Life Sci., 4(2):163-180.

Raman, P.G. (2016): Environmental Factors in Causation of Diabetes Mellitus, pp 231-245.. In: Environmental Health Risk-Hazardous Factors to Living Species. DOI: $10.5772 / 62543$

Rao, N.K. \& Nammi, S. (2006):Antidiabetic and renoprotective effects of the chloroform extract of Terminalia chebula Retz. seeds in streptozotocin-induced diabetic rats. $\underline{B M C}$ Complement. Altern. Med., 6(1):17.

Röder, P.V., Wu, B., Liu, Y. \& Han, W. (2016): Pancreatic regulation of glucose homeostasis. Exp. Mol. Med., 48(3):e219.

Senthilkumar, G.P. \& Subramanian, S.P. (2008): Biochemical studies on the effect of Terminalia chebula on the levels of glycoproteins in streptozotocin-induced experimental diabetes in rats. J. App. Biomed., (De Gruyter Open).,6(2):105115

Singh, A., Singh,K. \&Saxena, A. (2010):Hypoglycaemic activity of different extracts of various herbal plants. Int. J. Res. Ayur. Pharm. (IJRAP). 1(1):212-224.

Sri, K.S., Kumari, D.J. \& Sivannarayana, G. (2013): Effect of Amla, an approach towards the control of diabetes mellitus. Int.J.Curr.Microbiol. App. Sci., 2(9):103-108.

Rottschäfer, V. (2017): Analysisofglucose insulin glucagoninteraction models, pp. 1-57.. Bachelor-thesis. from, Leiden University Mathematical Institute. 